\title{
Alterações hematológicas em pacientes expostos cronicamente ao benzeno*
}

\author{
Hematological abnormalities in patients chronically exposed to benzene. An \\ update
}

\author{
Milton Artur Ruiz *", José Vassallo***, Cármino Antonio de Souza****
}

\begin{abstract}
Ruiz, M.A et al. Alterações hematológicas em pacientes expostos cronicamente ao benzeno. Rev. Saúde Pública, 27: 145-51, 1993. Foram apresentadas as alteraçōes hematológicas do sangue periférico e da medula óssea em pacientes expostos cronicamente ao benzeno. Foram descritos a biotransformação metabólica e os possíveis mecanismos envolvidos neste tipo de toxicidade. Os dados hematológicos do sangue periférico são mostrados e avaliados em sua importância, sendo a macrocitose e a linfocitopenia sinais precoces de toxicidade ao benzeno. As alterações da medula óssea observadas são demonstradas pelos métodos complementares citológico e histológico. A anormalidade histológica de maior importância foi a hipocelularidade global devida principalmente ao setor granulocítico. Foi observado também aumento do percentual de eosinófilos, de mastócitos e de atipias no setor megacariocítico. Foram observadas alteraçōes de caráter inflamatório e ressaltada a presença de sinais de dismielopoiese. Foram enfatizadas a necessidade da valorização das alterações hematológicas do sangue periférico e a visão critica e global desse importante problema de saúde pública.
\end{abstract}

Descritores: Benzeno, envenenamento. Doenças hematológicas, induzido quimicamente. Exposição ocupacional.

\section{Introduçáo}

O benzeno é um hidrocarboneto aromático que apresenta larga e diversificada aplicação industrial. Diversos produtos intermediários derivam do benzeno, sendo os mesmos utilizados como matéria prima ou solvente. A lista da participação do benzeno em atividades industriais é extensa, devendo ser ressaltada a sua participação na indústria siderúrgica e petroquímica, que são, assim, os principais ambientes de risco ocupacional e de exposição ao benzeno ${ }^{12}$.

A ação do benzeno em organismos vivos é conhecida e os efeitos deletérios a exposições agudas estão bem descritas ${ }^{16,25}$.

\footnotetext{
* Trabalho apoiado pelo Centro de Pesquisas "Dr. Eraldo Aurélio Franzese" - Faculdade de Ciências Médicas de Santos, Fundação Lusíada.

** Setor de Hematologia da Faculdade de Ciências Médicas de Santos (FCMS) - Santos, SP - Brasil.

*** Departamento de Anatomia Patológica da Faculdade de Ciências Médicas da UNICAMP - Campinas, SP - Brasil.

**** Disciplina de Hematologia e llemoterapia da Faculdade de Ciências Médicas da UNICAMP - Campinas, SP Brasil.
}

Separatas/Reprints: M.A. Ruiz - Av. Conselheiro Rodrigues Alves, 302 - 1101 5-202 - Santos, SP -Brasil

Edição subvencionada pela FAPESP. Processo Medicina 93/ 0208-5
As hemopatias estão entre os efeitos devidos a exposiçōes tanto agudas como crônicas, sendo descritos casos de anemia aplástica, leucemia e outras hemopatias malígnas em diversos paises $5,6,19,35$. A Primeira descrição dos efeitos do benzeno em trabalhadores remonta a 1897, com o relato de quatro casos de "púrpura hemorrágica" em uma fábrica da Suécia ${ }^{33}$. A descrição de um caso de leucemia aguda em um trabalhador exposto ao benzeno durante cinco anos consecutivos ocorreu em $1928^{17}$. A relação entre o benzeno e alterações hematológicas e a ocorrência de hemopatias malignas está documentada e descrita nos inúmeros trabalhos e diversas observaçōes realizadas $23,4,5,11,13,14,20,22,37$.

No início da década de 80, o Município de $\mathrm{Cu}$ batão, no Estado de São Paulo, passou a ocupar as páginas dos noticiários devido às denúncias da ocorrência de poluição ambiental decorrentes do parque industrial nele instalado ${ }^{21}$.

Estudos realizados em moradores de Vila Parisi, um bairro com aproximadamente 15 mil habitantes e cercado pela maioria das indústrias de $\mathrm{Cu}$ batão, mostraram altas taxas de concentração de metahemoglobina e de sulfa-hemoglobina em sua população ${ }^{23}$.

Os estudos citológicos desses moradores apresentaram, em $38 \%$, alteraçōes eritrocitárias isoladas ou combinadas, destacando-se a presença de 
policromatofilia, de pontilhados basófilos, de corpos de Heinz e de reticulocitose ${ }^{24}$.

A partir de 1979, trabalhadores da Companhia Siderúrgica Paulista (COSIPA) começaram a apresentar alteraçðes hematologicas quantitativas, com redução do número dos leucócitos conseqüente a redução dos neutrófilos. As manifestações clínicas desses pacientes eram vagas e inespecificas, porém, apresentavam em comum a exposição crônica ao benzeno, ora pela função, ora pelo ambiente em que exerciam suas atividades ${ }^{26}$. $O$ descontrole ambiental em relação ao benzeno era conhecido e a constatação da universalidade do mesmo foi realizada pela própria indústria sidenúrgica ${ }^{15}$.

A divulgação deste fato gerou desconfiança e, a partir de 1985, centenas de trabalhadores foram afastados de suas atividades por "leucopenia" que, de dado hematológico usual, passou a sinónimo de benzenismo $0^{9.26}$.

A partir de então, inúmeros trabalhos e relatos de observação de alteraçðes hematológicas em trabalhadores oriundos da indústria siderúrgica foram realizados, sendo o objetivo do presente trabalho apresentar e sistematizar os resultados encontrados, discutindo a sua importância em indivíduos expostos ao benzeno $7,8,9,10,15,16,28,29,30,31$.

\section{Benzeno}

O benzeno, juntamente com as radiaçð̃es ionizantes e determinados medicamentos utilizados no tratamento de neoplasias, tais como os alquilantes, os antimetabólicos e os inibidores da mitose, é considerado um agente mielotóxico regular e o contato ou uso dos mesmos conferem riscos potenciais de alteraçōes hematológicas.

A absorção do benzeno ocorre no homem principalmente pela inalação do vapor e secundariamente pela pele, pelo contato com sua forma líquida. $\mathrm{Na}$ Figura apresenta-se o esquema da biotransformação metabólica do benzeno, que, absorvido, é eliminado pelo ar, sendo exalado em quantidades que variam entre 10 a $50 \%$ do total inalado. $O$ que não for exalado penetra na circulação sanguínea, ocorrendo a sua metabolização através do fígado ou dos órgãos que contenham grandes quantidades de gordura como, por exemplo, a medula óssea.

A biotransformação do benzeno retido realizase pela via enzimática ou não. $O$ fenol é o produto mais abundantemente formado e é encontrado na urina sob a forma de sulfo ou de glicuro conjugados. A toxicidade medular do benzeno deve-se à sua capacidade de ligação de um ou mais metabólitos formados na biotransformação a macromoléculas, tais como o DNA e proteínas. Esta propriedade confere ao benzeno uma ação radiomimética, que é a responsável pela interferência nas células progenitoras da medula óssea e de dano ao microambiente medular.

A ação do benzeno sobre a medula óssea determina lesão central que é a responsável pelas alteraçōes hematológicas periféricas que se instalam e que são tardias e inespecíficas. A monitorização

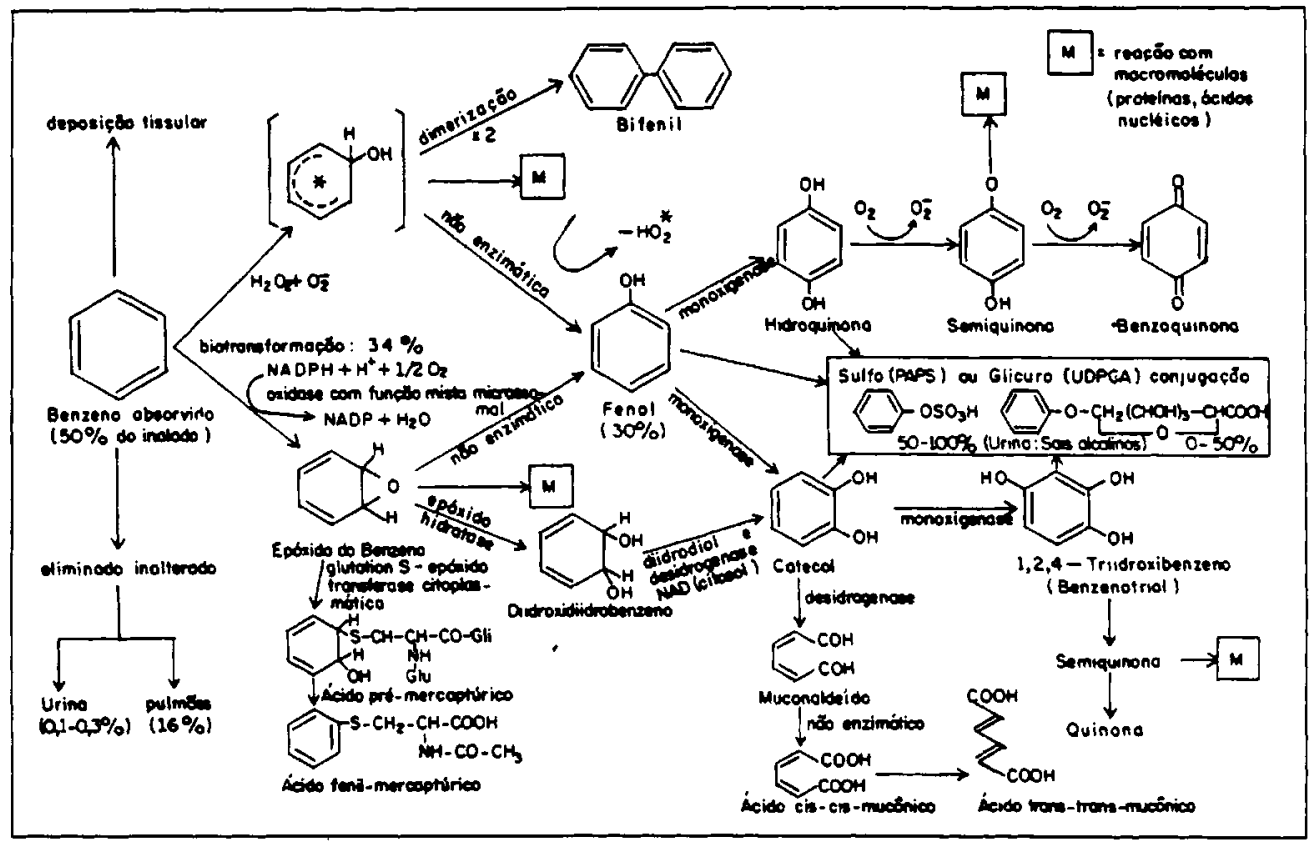

Figura. Biotransfo nação metabólica do Benzeno. Extraída de Azeveco12, 1990. 
biológica das exposiçðes ao benzeno são realizadas nos produtos da sua biotransformação metabólica e dentre eles citamos o fenol urinário como o de uso mais constante. O método encontra diversas críticas quanto à dificuldade de padronização e principalmente devido a inadequação para determinação de exposição a concentraçð̄es inferiores a 10 ppm do hidrocarboneto aromático ${ }^{32}$. Os outros métodos propostos para determinação de produtos de biotransformação apresentam diversos problemas de dificuldade analítica, e de padronização apesar do ácido S-fenil mercaptopúrico ser específico e promissor como indicador biológico a baixas concentrações ${ }^{32}$. Neste contexto é que a observação hematológica, pela sua simplicidade e facilidade de realização, passa a ter capital importância para avaliação dos possiveis expostos ao benzeno.

\section{Alteraçóes Hematológicas Perlféricas}

As alterações hematológicas periféricas de pacientes expostos cronicamente ao benzeno são extremamente variáveis, e a observação desses pa-

Tabela 1. Alteraçōes hematológicas periféricas observadas em pacientes cronicamente expostos.

\section{Série Vermelha}

Anemia, Macrocitose, Eritroblastos

Pontilhados Basofilos

Policromasia

Série Branca

Leucopenia, Neutropenia, Linfocitopenia

Leucocitose, Neutrofilia, Eosinofilia

Monocitose, Linfocitose

Série Plaquetária

Trombocitopenia, Macroplaquetas

Bicitopenia periférica

Pancitopenia periférica

Fonte: Ruiz27, 1987. cientes deve ser sistematizada, padronizada e seriada, com a finalidade de assegurar a constatação dessas anormalidades. Na Tabela 1, estão listadas as anormalidades descritas e observadas em diversos relatos ${ }^{1,8,36}$.

As alteraçðes da série vermelha podem ser: $a$ anemia, a macrocitose, a presença de pontilhado basófilo, a policromasia e os eritroblastos periféricos.

$\mathrm{Na}$ Tabela 2, estão apresentados os resultados do sangue periférico de 95 pacientes, nos quais observou-se a presença de anemia em somente um caso e de volume corpuscular médio (VCM) acima de 93 fl (macrocitose), em 18 casos. Esses dados corroboram o observado na literatura, principalmente no que tange a macrocitose. Goldstein ${ }^{18}$ enfatiza que 0 VCM elevado deve ser considerado como um sinal precoce de toxicidade de pacientes expostos ao benzeno. A presença deste dado deve ser valorizada com a devida cautela. A exclusão de hepatopatia e alcoolismo crốíico, ou de deficiência de vitamina B12, deve ser realizada concomitantemente à constatação da exposição crônica ao benzeno.

A anemia, o pontilhado basófilo, a policromasia e os eritroblastos periféricos devem ser considerados como sinais de alerta, e induzem ao estudo medular dos expostcs. A presença de anemia obrigará à pesquisa etiológica, que poderá ser devida a uma doença independente ou a toxicidade medular ao benzeno. Nos casos graves em que a insuficiência medular está definida, a anemia encontra-se sempre associada a citopenias dos outros setores. As alterações hematológicas quantitativas do setor branco estão listadas na Tabela 1.

Aksoy $^{1}, 1971$, relatou em trabalhadores expostos cronicamente ao benzeno que a leucopenia foi o dado mais frequientemente observado. A leucopenia por neutropenia $\varepsilon$ também a alteração hematológica relatada em pacientes das indústrias de Cubatão e tem sido considerada como "sinônimo de berzenismo"9,26. A leucopenia desses pacientes pode cccrrer por neutropenia isolada, que é o dado mais freqüente, ou por redução global de todos os leucócitos ou, mais raramente, por linfocitopenia.

Tabela 2. Estudo hematológico de sangue periférico en 95 pacientes expostos cronicamente ao benzeno.

\begin{tabular}{|c|c|c|c|c|c|c|c|}
\hline \multicolumn{2}{|c|}{ Eritrócitos/1 } & \multicolumn{2}{|c|}{ Hemoglobina/d! } & \multicolumn{2}{|c|}{ Hemąiócrito } & \multicolumn{2}{|c|}{ Vol. Corpusc. Médio (fl) } \\
\hline Valores & $N \%$ & Valores & $\mathbf{N} \%$ & Vaicres & $N \%$ & Valores & $N \%$ \\
\hline 3499 a $3999 \times 10^{12 / 1}$ & $1(01,05 \%)$ & $<12,9$ & $7(07,37 \%)$ & $<39 \%$ & $3(03,16 \%)$ & $<76,9$ & $1(01,05 \%)$ \\
\hline 4000 a $4999 \times 10^{12 / 1}$ & $5(05,26 \%)$ & $>12,9$ & $88(92,63 \%)$ & 35 a $41 \%$ & $4(04,21 \%)$ & 76,9 a $93 f l$ & $1(01,05 \%)$ \\
\hline$>5000 \times 1012 / 1$ & $89(93,69 \%)$ & & & $>42 \%$ & $88(92,63 \%)$ & $>94 \mathrm{fl}$ & $18(18,95 \%)$ \\
\hline $\mathrm{x}$ & $4925 \times 10^{12 / 1}$ & $x$ & $14,532 \mathrm{~g} / \mathrm{dl}$ & $x$ & $44,6 \%$ & $x$ & $89,73 f 1$ \\
\hline DP & 341,41 & DP & 1,05 & DP & $2,7 \%$ & DP & $6,89 f 1$ \\
\hline$M$ & $4900 \times 10^{12 / 1}$ & $M$ & $14,5 \mathrm{~g} / \mathrm{dl}$ & $M$ & $45 \%$ & $M$ & $90 \mathrm{fl}$ \\
\hline
\end{tabular}

$L=$ Litro $\quad X=$ Média $\quad M=$ mediana $\quad D P=$ Desvio Padräo $\quad F L=$ Fentolitros $\quad D I=$ Decilitro

Fonte: Ruiz e col.30 (1991) 
Tabela 3. Contagem diferencial dos leucócitos de 95 pacientes expostos cronicamente ao benzeno.

\begin{tabular}{lccccccc}
\hline & $0.0,2 \times 10 \% / 1$ & $0,21-0,5 \times 109 / 1$ & $0,51-1,5 \times 109 / 1,51-2,0 \times 109 / 1$ & $2,1-4,0 \times 109 / 1$ & $>4 \times 119 / 1$ & $\times$ & $M$ \\
\hline Leucócitos & - & - & - & $54(57,9 \%)$ & $41(42,1 \%)$ & 37793800 \\
Neutrófilos & - & - & - & $95(100 \%)$ & - & - & 1436 \\
Linfócitos & - & - & $19(20 \%)$ & $76(80 \%)$ & - & - & 1930 \\
Monócitos & $63(63,3 \%)$ & $32(33,7 \%)$ & - & - & - & - & 1620 \\
Eosinófitos & - & $69(73,6 \%)$ & $26(27,4 \%)$ & - & - & - & 300 \\
\hline
\end{tabular}

$L=$ Litro $\quad X=$ Média $\quad M=$ mediana

Fonte: Ruiz e col.30 (1991)

Na Tabela 3 estão apresentados os resultados da contagem diferencial dos leucócitos em grupo de pacientes estudados, no qual o critério de seleção, além do nexo causal de exposição ao benzeno, da ausência de doença prévia e do uso de medicamentos, foi a presença do número de neutrófilos abaixo de $2.000 /$ $\mathrm{dl}^{16}$. Observamos em 19 casos a presença de linfocitopenia. Goldstein ${ }^{18}$ considera que a linfocitopenia deve ser valorizada; em conjunto com a macrocitose, são os sinais hematológicos mais precoces da toxicidade ao benzeno $0^{9}$. Esta assertiva é compartilhadapor Sawahata e col. ${ }^{34}$. Outras alterações hematológicas também estão relatadas na literatura ${ }^{1,8,27,36}$. Sua valorização depende da exclusão de outros agentes etiológicos possíveis. Isto ocorre com a eosinofilia, o uso de medicamentos, as anomalias hereditárias e com a presença de hiposegmentação dos neutrófilos (Anomalia de Pelger Huet) ${ }^{30}$.

A presença de trombocitopenia isolada e de macroplaquetas é uma alteração que também se encontra descrita na literatura ${ }^{1}$. A observação dos dados relativos à série plaquetária, assim como de outras alterações hematológicas periféricas, exige experiência e atenção. A sistematização da coleta de sangue e a padronização dos métodos de determinação dos parâmetros hematológicos, além da calibragem e aferição constante dos equipamentos, são necessárias, acrescida de uma detalhada observação microscópica. O conhecimento da possibilidade de ocorrência de alterações em expostos ao benzeno, aqui apresentadas, é de capital importância parå o médico do trabalho em sua atividade, para se posicionar em relação ao trabalhador sob risco funcional ou ambiental. A constatação seriada da anormalidade hematológica obrigará o monitoramento deste paciente e acompanhamento hematológico, com conseqüente avaliação da necessidade de procedimentos e investigaçð̄es adicionais.

\section{Alteraçóes Hematológicas Centrais-Medula Óssea}

O estudo da medula óssea para observação dos expostos cronicamente ao benzeno deve ser reali- zada tanto do ponto de vista citológico, como histológico, com a finalidade de compensação e complementacão de ambos os métodos.

O estudo citológico poderá ser realizado pela punção de agulha de aspiração (mielograma), ou pelo método de aposição ("imprint") do fragmento ósseo, obtido através de agulha de biópsia medular. Em ambas as situaçðes, quando da obtenção do material, o médico deve se certificar da presença de material citológico no esfregaço ou "imprint", para que a interpretação não seja prejudicada. Esses cuidados farão com que a correlação citológica e a histológica seja fidedigna e conclusiva. O estudo citológico da medula óssea apresenta a vantagem do detalhe, tendo porém a desvantagem, em relação ao método histológico, da avaliação da celularidade medular. Para tanto, esta avaliação deve ser global $\mathrm{e}$, de preferència, no local das espículas ósseas do esfregaço. A contagem diferencial deve ser realizada em 500 células. As alteraçōes citológicas observadas poderão ser quantitativas ou qualitativas (Tabela 4 ). Em estudo de 35 pacientes ${ }^{28}$, em que se procurou correlacionar a citologia e a histologia de pacientes neutropênicos expostos, observou-se a hipocelu-

Tabela 4. Alterações citológicas da médula óssea relacionadas à exposição ao benzeno.

a) Quantitativas

Redução da relação granulócito/eritroblástico (G/E)

Hipocelularidade isolada: Eritroblástica

Granulocítica

Megacariocitica

Hipercelularidade isolada: Eritroblástica Granulocítica megacariocitica

Hipocelularidade combinada

Hipocelularidade global

Eosinofilia

b) Qualitativas

Setor Eritroblástico

Setor Grar ulocítico

Setor Meç acariocítico 
laridade global em $3 / 4$ dos casos, com redução da relação granulocítico/eritroblástico (G/E) em $85,7 \%$, sendo que em $63,3 \%$ esta relação estava abaixo de 2,0 (normal esperado acima de 3,0). $O$ estudo citológico constatou que houve uma redução da relação $\mathrm{G} / \mathrm{E}$ e que isso era devido a hipocelularidade do setor granulocítico. Este foi o dado quantitativo mais importante observado pela citologia da medula óssea. Dentre as alterações qualitativas observadas, assumem importância, no estudo citológico, as alterações do setor eritroblástico. Os dados morfológicos observados são de diseritropoiese, com um aumento substancial de eritroblastos picnóticos, de transição, assim como a presença eventual de figuras eritrocitárias aberrantes.

No setor granulocítico, observaram-se desvios de maturação e um dos casos do estudo apresentava um percentual de $8 \%$ de células blásticas na contagem diferencial. A presença de alterações morfológicas no setor de megacariocítico pode ser evidenciada pela presença micromegacariócitos. $O$ estudo histológico da medula óssea é realizado em fragmentos ósseos obtidos comumente da espinha iliaca póstero-superior dos pacientes. Para tanto, são utilizadas agulhas de biópsia especiais, de procedência nacional ou estrangeira, similares à de Jamshidi. A melhoria no desenho das agulhas de biópsia, e o desenvolvimento de novos fixadores dos fragmentos ósseos, reduziram os artefatos técnicos e melhoraram sobremaneira a resolutividade da microscopia, propiciando laudos técnicos precisos e detalhes que se aproximam aos da citologia.

O método propicia uma vantagem de avaliação da celularidade, propicia também a avaliação do tecido adiposo, a observação das trabéculas ósseas e do estroma. Os cortes histológicos habitualmente são corados pela Hematoxilina-Eosina (HE), pelo azul da Prússia (Perls), para avaliação dos depósitos de ferro intramedular e impregnação pela prata (Gomori), com a finalidade de se observar a distribuição das fibras de reticulina. Podem ser requisitadas colorações adicionais e reaç̄es imunohistoquímicas e as suas indicações dependerão do objetivo do estudo. Na Tabela 5, encontram-se listadas as alterações passíveis de screm encontradas e, à luz das presentes observações e de trabalhos recentes, são comentados os achados histológicos em pacientes expostos cronicamente ao benzeno ${ }^{10,28,29,30,31}$.

As alterações histológicas em pacientes expostos cronicamente ao benzeno são variadas, porém um determinado padrão é observado. Fazem parte desse padrão a redução da celularidade global, às custas da hipocclularidade granulocítica e da presença frequiente de focos hipocelularidade intensa. É observado tarnbém aumento do percentual de
Tabela 5. Alteraçôes citológicas da médula óssea relacionadas à exposição ao benzeno.

Aumento do tecido adiposo

Alterações do Estroma: Edema interstical

Hemorragia

Necrose Tissular

Fibrose Reticulínica

Tecido Hemopoiético

a) Quantitativas:

Hipocelularidade setorial isolada Hipocelularidade setorial combinada

Hipocelularidade global

Eosimofilia

Mastocitose

b) Qualitativa:

Setor Eritroblástico
Setor Granulocítico
Setor Megacariocítico
Dismielopoiese
Precursores imaturos de locali-
zação anômala (ALIP)

eosinófilos, de mastócitos e de atipias no setor megacariocítico, com a presença de micromegacariócitos, megacariócitos hipotróficos e pleomórficos. O tecido ósseo e as trabéculas ósseas encontram-se comumente preservadas, havendo, no entanto, alteraçð̃es estromais como edema intersticial, focos hemorrágicos e necrose tissular, que são evidenciadas à medida em que existe melhoria da técnica histológica. O tecido hemopoiético, como citado, poderá ter comprometimento quantitativo dos três setores, havendo, no entanto, redução quase sempre mais pronunciada no setor granulocítico, provavelmente o mais sensível dentre todos. No entanto, associadas à hipocelularidade do setor granulocítico, são observadas reduçð̃es combinadas com o setor eritroblástico, conferindo, em determinadas condições mais graves, o quadro de aplasia medular. A hipocelularidade global pode ocorrer, e na realização desta estimativa é importante a observação concomitante das alteraçōes estromais.

Asscciada às lesões do estroma, tem importância $o$ aumento percentual de eosinófilos e de mastócitos que, juntamente com a hipocelularidade global, caracterizam uma medula agredida e sob a ação tóxica. A fibrose reticulínica é outro dado observado, e é sinal de desorganização da estrutura reedular. As observaçōes das alterações qualitativas apresentam limitaçð̄es em relação ao método citológico, porém as dificuldades vêm sendo suplantadas, paulatinamente, com a melhoria dos métodos de fixação e de coloração, além de uma maior experência na interpretação dos dados observados. As alterações qualitativas mais pronunciadas encontram-se no setor megacariocítico. Neste, observamos os micromegacariocítos e me- 
gacariócitos hipotróficos, caracterizando uma dismegacariocitopoiese. Desvios de maturação no setor granulocítico também são observados, e medulas dismielopoiéticas ocorreram em nossas observaçðes. Outro dado recente de alteraçōes qualitativas observadas em medula óssea de expostos, refere-se à presença de precursores imaturos de localização anormal (ALIP). Em uma série de 65 pacientes, foi observado em $8 \%$ dos casos, a presença de "ALIP" o que é considerado um dado proeminente de dismielopoiese ${ }^{10}$. Ressalta-se a presença de casos da síndrome mielodisplásica clássica com a de citopenias periféricas e de medula normo ou hipercelular, como alteração possível em expostos cronicamente ao benzeno.

\section{Conclusóes}

Após a apresentação dos presentes dados, e do conhecimento que o benzeno é um agente mielotóxico inequívoco, a caracterização da alteração hematológica periférica, associada ao nexo causal, obriga à realização de medidas preventivas em relação a continuidade da exposição. As alteraçð̃es hematológicas periféricas são variadas e nenhuma delas é concludente em relação ao benzeno. Porém a macrocitose, a linfocitopenia e principalmente a neutropenia que se instala, estão dentre as anormalidades que devem merecer cuidadosa observação. A medula óssea não deve ser um método de diagnóstico isolado, visto que as alteraçōes observadas não são patognomônicas de exposição crônica ao benzeno, havendo a possibilidade da ocorrência das mesmas por outros agentes tóxicos. A história clínica, epidemiológica e osupacional, o conhecimento dos resultados hematológicos do sangue periférico, desde a sua admissão, até a constatação e caracterização da anormalidade, propiciará emprego de técnicas de estudo, como o de medula óssea o que complementará e diagnosticará uma ação mielotóxica do benzenono.

No momento atual, pela vigêr.cia de casos de expostos, deve-se envidar esforços para a busca de testes preditivos de anormalidades citogenéticas e imunológicas, além de estudos funcionais, afim de aumentar o conhecimento da ação do benzeno no organismo humano, propiciando açōes que beneficiem os trabalhadores potencialmente e presumivelmente expostos aos hidrocarbonetos aromáticos.

RUIZ, M.A et al. [Hematological abnormalities in patients chronically exposed to benzene. An update]. Rev. Saúde Pública, 27: 145-51, 1993. A study was carried out into the hematological abnormabilities of peripheral blood bone marrow in patients chronically exposed to benzene. The metabolic biotransformation and the mechanisms involved in toxicity are described. Hematological data are described and discussed. Macrocytosis and lymphopenia are the earlieste hematological signs of benzene toxicity. Bone marrow abnormabilities are demostrated by the complementary methods of cytology and histology. Global hypocellularity was mainly due to the granulocytic series. Mastocytosis, eosinophilia and magakariocytic abnormalities are also presented. Inflamatory abnormalities and signs of dismyelopoiese could also be observed. The importance of peripheral blood abnormalities and the need for a critical approach to this important public health problem are emphasized.

Keywords: Benzene, poisoning. Hematologic diseases, chemically induced. Occupational exposure

\section{Referénclas Bibliográficas}

1. AKSOY, M.; DINÇOL, K.; AKGUN, T. Hematological effects of chronic benzene poisoning in 217 workers. $\mathrm{Br}$. J.Ind. Med., 28: 296, 1971.

2. AKSOY, M. et al. Acute leukemia due to chronic exposure to benzene. Am. J. Med., 52:160-6, 1972.

3. AKSOY, M. ERDEM, S.; DINÇOL, G. Types of leukemia in a chronic benzene poisoning a study in 34 patients. Acta Haematol., 55: 65, 1976

4. AKSOY, M. Leukemia in workers due occupational exposure to benzene. N. Istambul Contr. Clin. SCI ., 12: 3, 1977.

5. AKSOY, M Different types of malignancies due to occupational exposure to benzene. A review of recent observations in Turkey. Environm. Res., 23: 181, 1980.

6. AKSOY, M. et al. Aplastic anemia due to chemicals and drugs; a study of 108 patients. Sex. Transm. Dis., 11 (4 suppl): 347-50, 1984.

7. AKSOY, M. Benzene as a leukemogenic and carcinogenic agent. Am. J. Ind. Med., 8: 9, 1985.

8. AKSOY, M. et al. Exposure to benzene in turkey between 1983 and 1985: a hematological study on 231 workers. Br. J.Ind. Med., 44: 785-7, 1987.

9. AUGUSTO, L.G.S. Benzolismo em uma siderírgica. Rev. S.O.S., 10: 153-87, 1984

10. AUGUSTO, L.S.G. Estudo longitudinal e morfológico (medula ossea) em pacientes com neutropenia secundária a exposição ocupacional crônica ao benzeno. Campinas, 1991. [Dissertaçăo de Mestrado - FCM/ UNICAMP].

11. AUSTIN, H.; DELZELL, E.; COLE, P. Benzene and leukemia a review of the literature and risk assessment. Am. J. Epidemiol., 127: 419-39, 1988.

12. AZEVEDO, F.A. Breves referenciasis aos aspectos toxicológicos do benzeno. Salvador. Fundação José Silveira, 1990.

13. BERNARD, J. The epidemiology of leukemias: past, present, future. Nouv. Rev. Fr. Hematol., 31: 103-9, 1989.

14. BRAND, L. Leukemia and lymphoma risks derived from solvents. Med. Oncol. Tumor. Pharmacother., 4: 199205, 1987.

15. COMPANHIA SDERURRICA PAULISTA (COSIPA) Estudo sobre leucopenia. Gomes Editora e Consultoria de Comunicação Empresarial, 1986.

16. CRONKITE E. P. Chemical Leukemogenesis: benzene as a model. Sem. Hematol., 24: 2-11, 1987. 
17. DELORE, P. \& BORGOMANO, C. Leucémie aigué an cours de l'intoxication benzénigne: sur l'origine toxique de certaines leucemies aigués et leur relations avec les antmies graves. J. Med. Lyon, 9: 227-33, 1928.

18. GOLDSTEIN, B D. Biological and ambient monitoring of benzene in the workplace. J. Occup. Med., 28: 1051, 1986.

19. HU, H. Benzene - Associated myelofibrosis (letter) Ann. Intern. Med., 106: 171-2, 1987

20. JACOBS, A. Benzene and leukemia. Br. J. Hematol., 72: 119-21, 1989.

21. KUCINSKI, B. Cubatão uma tragédia ecológica. Ciênc. Hoje., 1: 11, 1982.

22. MCMICHAEL, A. J. Carcinogenicity of benzene, towene and $x y l e n e:$ epidemiological and experimental evidence. Lyon, IARC, 1988. (IARC-Scient. Publ., 85).

23. NAOUM, P. C. et al. Toxic methaemoglobinaemia and sulphaemoglobinaemia in a population from Cubatão (S.Paulo, Brazil): effect of industrial pollution? Ciênc. Cult., 34: 529, 1982.

24. NAOUM, P. C.; MOURÃO, C. A.; RUZZ, M. A. Alteraçōes hematológicas induzidas por poluiçăo industrial em moradores e industríarios de Cubatão, SP (Brasil). Rev. Saúde Pública 18: 271-7, 1984.

25. PEZZANO, G. Rischio da benzene. Milano, La goliardia Pavese, 1989.

26. RUIZ, M. A. O problema de leucopenia em Cubatão. Bol. Soc. Bras. Hematol. Hemat., 7: 171-2, 1985.

27. RUIZ, M. A. Alteraçōes hematológicas do benzenismo. Bol. Soc. Bras. Hematol. Hemat., 9: 129-34, 1987.

28. RUIZ, M. A et al. Correlação de estudo citológico e histológico de medula óssea em pacientes neutropênicos oriundos de uma indústria sidenúrgica de Cubatåo, SP. Bol. Soc. Bras. Hematol. Hemat., 10: 84, 1988.
29. RUIZ M. A. et al. Resultado histológico da medula bssea (BMO) de 135 pacientes de um serviço de medicina ccupacional. Bol. Soc. Bras. Hematol. Hemat., 12: 81,1990 .

30. RUIZ, M. A.; VASSALLO, J.; SOUZA, C. A. Morphologic study of the bone marrow o neutropenic patients exposed to benzene of metallurgical industry of Cubatano, S.Paulo, Brasil. J. Occup. Med., 33: 83, 1991.

31. RUIZ, M. A. et al. Bone marrow morphology in patients with neutropenia due to chronic exposure to organic solvents (Benzene): early lesions. Pathol. Res. \& Practice. 1993 [In press].

32. SALGADO, P. E. T. \& PEZZANO, G. Indicadores biologicos de exposição ao benzeno. Rev. Bras. Saúde Ocup., 19: (74): 25-31,1991.

33. SANTESSON, G.G. Uber chronische vergiftungen mit steinkohlentheerbenzin. Arch.Hyg. Berl. , 31: 336-76, 1987.

34. SAWAHATA, T. et al., Metabolism of benzene and its metabolites in bone marrow in toxicology of the blood and marrow target. New York. Raven Press., 1985. (Organ toxicology series Richard D. Irons).

35. VINEIS, P. \& SENIORI, C. A. Italian multicentre study hematolympoieticmalignancies. Med.Lav., 81: 506-12, 1990.

36. WAKAMATSU C. T. Contribuiçâa ao estudo da exposição profissional ao benzeno em trabalhadores de indústria de calçados - Sāo Paulo. Sāo Paulo, 1976. [Dissertação de Mestrado - Faculdade de Saúde Pública da USP].

37. YIN, S.N. et al. Leukemia in benzene workers; a retrospective cohor study. Br.J. Ind.Med, 44: 124-8,1987.

Trabalho recebido para publicaçđo em 215.1992

Reapresentado em 1.2.1993 Aprovado para pubicaçāo em 1.3.1993 